\title{
The Impact Of Education On Economic Growth: The Case Of Mauritius
}

Mohun P. Odit, University of Technology, Mauritius

K. Dookhan, University of Technology, Mauritius

S. Fauzel, University of Technology, Mauritius

\begin{abstract}
This paper focuses on the impact of investment in education on economic growth in Mauritius. It is an attempt to explore the extent to which education level of the Mauritian labour force affects its economic growth that is its output level. We have used the Cobb-Douglas production function with constant returns to scale where human capital is treated as an independent factor of production in the human capital augmented growth model. We expect to contribute to the existing literature by bringing evidence from a data set for the period 1990 to 2006 obtained from the central statistical office and Bank of Mauritius reports. The results reveal that human capital plays an important role in economic growth mainly as an engine for improvement of the output level. There is compelling evidence that human capital increases productivity, suggesting that education really is productivity-enhancing rather than just a device that individuals use to signal their level of ability to the employer.
\end{abstract}

Keywords: Human Capital, Education and Economic Growth

\section{INTRODUCTION}

$\mathcal{G}^{3}$ n every budget the government of Mauritius announces various developments to be done in the education sector with high government expenditures diverted towards it. The motivation for such an increase lies in the belief that the education of children in developing countries is crucial for future economic growth and lasting democracy, thereby leading to a greater stability and improved standards of living. Becker (1964) and Mincer (1974) have argued the importance to characterise the benefits of education by means of the notion of investment in human capital. This idea captures the fact that investment in human beings, like investment in tangible forms of capital such as buildings and industrial equipment, generates a stream of future benefits. Human capital is one of the big unknowns of research on the determinants of economic development. The majority of empirical and theoretical literature suggests the existence of a relationship between social indicators and economic growth. Education is regarded as an investment in human capital, since benefits accrue to an educated individual over a lifetime of activities.

There are various debates over whether changes in educational attainment do affect the long-run growth rate of an economy. The macroeconomic evidence on level effect is consistent with microeconomic estimates of private rates of return to schooling, it appears, however, that there are also significant long-term growth effects that is the more educated is the workforce, the better it is able to implement technological advances. Many growth models include education and offer predictions as to the implications of education policy changes on macroeconomic performance. Some empirical analysis of the growth rate of real per capita GDP in the U.S. suggest that years of secondary and higher schooling contribute positively towards economic growth. Such research is of particular importance as developed nations continue in taking a more active role in the development of third-world nations, as growth models offer important predictions that are useful in aiding policy decisions.

Human capital plays different roles in various theories of economic growth. The main theoretical approaches of modelling the linkages between human capital and economic performance are the neoclassical growth models of Robert Solow (1957) and the model of Romer (1990). 
Aghion and Howitt (1998) observed that the role of human capital in endogenous growth models which can be divided into two broad categories. The first category broadens the concept of capital to include human capital that is sustained growth is due to the accumulation of human capital over time as per Robert Solow (1957). The second category of model attributes growth to the existing stock of human capital, which generates innovations or improves a country's ability to imitate and adapt to new technology. This, in turn, leads to technological progress and sustained growth as mentioned by Paul Romer (1990).

In the developing world in particular, the primary avenue for technical progress is the adaptation of preexisting products and production methods to local economies. Often, tiny changes in production processes already in existence provide important improvements in productivity. In developing countries, the skills and knowledge required to adapt new technology to the local environment are typically scarce, and thus a learning process is necessary. Learning occurs through a combination of three factors: experience gleaned from the act of production: knowledge capital imported from the developed world; and conscious accumulation of know-how. Producers must develop the know-how to choose which technology to purchase, adapt it to the local economy and then use it efficiently. Formal schooling may reduce the cost of acquiring such know-how, thereby facilitating the adoption of innovations. The externality arises if those without schooling copy the adoption behaviour and productive practices of the educated as argued by Knight and Weir (2000).

Appiah and McMahon (2002) estimated net education effects beyond just growth and health effects on other key measures of development in Africa, and also a new view of indirect feedbacks on economic growth and of externalities. The effects are shown to improve infant mortality, increase longevity, and strengthen civic institutions and democratization, increase political stability, and increase investment in physical capital, which in turn have positive delayed feedback effects on the economic growth process. The effects also lower fertility rates and population growth rates. They also found the significant net education effects reducing poverty, inequality and crime.

This paper attempts to add to the existing literature by bringing new evidence on the relationship between education and economic growth and also investigate whether formal models shed any light on the claim that education plays a central role in growth. Can the possible role of education be given a secure foundation in terms of economic theory? Do the models capture the growth effects of education, as it is generally defined and understood? The remainder of the paper is organized as follows. Section 2 provides a brief empirical review of the perspective of the growth theory. Section 3 provides the link between education and economic growth. Section 4 describes econometrics analysis adopted to explain the relationship between education and economic growth. Section 5 reports the results of the findings. We conclude in section 6.

\section{THE PERSPECTIVE OF THE GROWTH THEORY}

One of the most prominent and influential contributions is that of Lucas (1988), which is in turn related to previous work by Uzawa (1965). In these models, the level of output is a function of the stock of human capital. In the long run sustained growth is only possible if human capital can grow without bound. That makes it difficult to interpret the Uzawa-Lucas conception of human capital in terms of the variables traditionally used to measure educational attainment, such as years of schooling. Their use of the term 'human capital' seems more closely related to knowledge, rather than to skills acquired through education.

Bils and Klenow (2000) argued that one way to relate the Uzawa-Lucas model is that the quality of education could be increasing over time. In this view, the knowledge imparted to school children in the year 2000 is superior to the knowledge that would have been imparted in 1950 or 1990 and will make a greater difference to their productivity in later employment. Even if average educational attainment is constant over time, the stock of human capital could be increasing in a way that drives rising levels of output. Yet this argument runs into difficulties, even at the level of university education. There may be some degree courses in which the knowledge imparted currently has a greater effect on productivity than before (medicine and computer science) but there is other, less vocational qualifications for which this argument is less convincing.

An alternative class of models places more emphasis on modelling the incentives that firms have to generate new ideas. Endogenous growth models based on the analysis of research and development, notably the 
landmark contribution of Romer (1990), yield the result that the growth rate partly depends on the level of human capital. The underlying assumption is that human capital is a key input in the production of new ideas. In contrast with the Uzawa-Lucas framework, this opens up the possibility that even a one-off increase in the stock of human capital will raise the growth rate indefinitely.

In practice, the generality of these results, and the contrast with the Uzawa-Lucas model, should not be overdrawn. The Uzawa-Lucas framework can be seen as a model of knowledge accumulation in a similar spirit to that of Romer, but easier to analyze and restrictive assumptions are needed to yield the Romer result that the longrun growth rate depends on the level of human capital Jones (1995). But even under more general assumptions, a rise in the level of human capital is likely to be associated with a potentially substantial rise in the level of output, brought about through a transitional increase in growth rates.

Another interesting aspect of growth models as argued by Rustichini and Schrnitz (1991) is that individuals may under-invest in education. They presented a model in which individuals divide their time between production, original research, and the acquisition of knowledge. Each individual knows that acquiring knowledge through education will raise their productivity in subsequent research, but since they do not fully capture the benefits of research, they will tend to spend less time in acquiring knowledge relative to the socially optimal outcome. They found that although policy intervention has only small effects on the allocation of time to education, it can have a substantial effect on the growth rate. Romer (2000) maintained that models of growth driven by Research and Development (R\&D) are determined by the quantity of inputs and not simply the expenditure upon it. Incentives like tax credits to encourage R\&D may be ineffective unless they encourage a greater number of scientists and engineers to work towards developing new ideas.

In most endogenous growth models based on research and development, the stock of human capital is taken to be exogenously determined. Acemoglu (1997) and Redding (1996), have relaxed this assumption, and considered what happens when individuals can choose to make investments in education or training, while firms make investments in R\&D. For some parameter values multiple equilibrium are possible, since the incentives of workers to invest in human capital, and those of firms to invest in R\&D are interdependent.

\section{EVIDENCE ON EDUCATION AND GROWTH}

Bils and Klenow (2000) found that greater schooling enrolment in 1960 consistent with one more year of attainment is associated with a faster annual growth over 1960-90. According to them, this conclusion is robust in allowing a positive external benefit from human capital to technology. Their results are consistent with Barro (1995) in which transitional differences in human capital growth rates explain temporary differences in country growth rates.

Mankiw et al (1992) and Barro (1991) investigated the link between education and economic growth. They examined variations in school enrolment rates, using a single cross-section of both the industrialised and the lessdeveloped countries. Both studies concluded that schooling has a significantly positive impact on the rate of growth of real GDP. Barro and Sala-i-Martin (1995) also investigated the impact of educational expenditures by governments. Their findings showed a strong positive impact. Using instrumental variable techniques to control for simultaneous causation, their regressions suggest that the annual rate of return on public education is of the order of twenty percent.

Pritchett (2001) has argued that poor policies and institutions have hampered growth in many of the least developed economies, directing skilled labour into relatively unproductive activities, hence disrupting the statistical relationship between education and growth in samples that include less-developed economies. Krueger and Lindahl (2001) suggest that the problem of unobserved variation in educational quality is exacerbated in panel data. Taking data quality into account, they show that increases in the stock of schooling do improve short-run economic growth. Hanushek and Kimko (2000) confirm that direct measures of labour-force quality, from international mathematics and science test scores, are strongly related to growth. Temple (2001) finds that growth effects are positive, but nonlinear. These non-linear effects may be missed by studies that impose linearity. 
A series of subsequent studies ${ }^{1}$ made use of panel data, examining changes over time in both education and growth. Several of these panel studies failed to detect any significant relationship between the rate of increase of educational capital and the rate of economic growth. They suggested that the positive findings of the earlier crosssection studies were due to omitted variable bias, failing to control for country specific effects. Benhabib and Spiegel (1994) compared models that treat human capital as a direct input into production with models treating human capital as an intermediate input into the acquisition of skills and/or knowledge. The former implies a relationship between output growth and educational growth, whereas the latter implies a relationship between output growth and the average stock of human capital per worker. Their econometric evidence favours the latter model. A more educated workforce can more readily identify, adapt and implement new ideas whether the ideas are generated domestically or overseas.

Teixeira and Fortuna (2003) studied human capital effects on economic growth of Portugal from 1960 to 2001. By using VAR and co integration analyses, they confirm that human capital and indigenous innovation efforts are enormously important to the process of Portuguese economic growth during the period 1960-2001, though the relevance of the former overpasses that involving the creation of an internal basis of R\&D. In addition, the indirect effect of human capital, through innovation, emerges as critical, showing that a reasonably higher stock of human capital is important to enable a country to reap the benefits of its innovation indigenous efforts.

\section{ECONOMETRICS ANALYSIS}

The main focus of this paper is to study the extent to which education level of the Mauritian labour force affects its economic growth that is its output level. A Cobb-Douglas production function with constant returns to scale is used where human capital is treated as an independent factor of production in the human capital augmented growth model to examine the effect of education on economic growth (the model has been adapted from Leoning (2002)) which is as follows:

$$
\mathrm{Y}=C K^{a} H^{\beta} L(1-a-\beta)---- \text { Equation-(1) }
$$

Where $a, \beta$ and 1- $a-\beta$ represent the elasticity of production relative to capital, human capital and labour respectively. Y represents output and $C$ is the level of technology or total factor productivity. $K, H$ and $L$ are physical capital, human capital and labour respectively. Multicollinearity between capital and labour is avoided by standardizing output and the capital stock by labour units which also impose the restriction that the scale elasticity of the production factors is equal to unity. In per-worker terms, this is as follows:

$$
y=C k^{a} h^{\beta}---- \text { Equation }-(2)
$$

Where $y=Y / L$ and $k=K / L$ are output and physical capital in intensive terms and $h=K / L$ stands for average human capital. Taking log on both sides the production function can be estimated as:

$$
\ln y=\ln C+a \ln k_{t}+\beta \ln h_{t}+\mu_{t}---- \text { Equation }-(3)
$$

The equation (3) appears suitable for estimation. However, some problems may arise since most macroeconomic time-series contain unit roots and that regression of one-stationary series on another is likely to yield spurious results. A well-known difficulty with estimating aggregative production functions is the possibility of a correlation between the error term and the regressors which would yield biased coefficient estimates. For example, a stochastic shock to the production function would typically be expected to result in the faster growth of accumulated inputs in that period. If shocks are also persistent, this will induce a positive correlation between future shocks and future levels of physical and human capital. By transforming the time series to stationarity by first differencing, the estimation bias can be removed. However, in any case this will create its own problems, notably because of the risk in losing information on the long run relationships of the variables.

\footnotetext{
${ }^{1}$ Benhabib and Spiegel (1994), Islam (1995) and Caselli el al. (1996)
} 
One approach in dealing with this dilemma is to employ an error correction model which combines longrun information with a short-run adjustment mechanism. The error-correction model may be estimated in two ways. The generalized "one-step" error correction model is a transformation of an autoregressive distributed lag model. As such, it can be used to estimate relationships among non-stationary processes. In order to estimate the human capital augmented production function, the error-correction model may be written as follows:

$$
\Delta \ln y_{t}=y_{1} \Delta \ln k_{t}+y_{2} \Delta \ln h_{t}-y_{3}\left(\ln y_{t-1}-\alpha \ln k_{t-1}-\beta \ln h_{t-1}-\ln C\right)+u_{t}---- \text { Equation-(4) }
$$

Since we do not have information on $\alpha$ and $\beta$, the equation can be transformed as follows:

$$
\Delta \ln y_{t}=\ln C+y_{1} \Delta \ln k_{t}+y_{2} \Delta \ln h_{t}-y_{3} \ln y_{t-1}+y_{4} \ln k_{t-1}+y_{5} \ln h_{t-1}+u_{t}---- \text { Equation-(5) }
$$

Estimates of the parameter $y_{3}$ can be used to calculate the required elasticities $\alpha$ and $\beta$. The coefficient $y_{3}$ contains additional information because it can be interpreted as a measure of the speed of adjustment in which the system moves towards its equilibrium on the average. Once the overall model has been found satisfactory, equation (3) is reformulated in order to incorporate an error-correction term. This "two-step" procedure, in which the error-correction term $E C_{t-1}$ is derived from the lagged residuals $u_{t}$ of the levels regression in equation (2) and can be used to estimate the following model:

$\Delta \ln y_{t}=\ln C+y_{1} \Delta \ln k_{t}+y_{2} \Delta \ln h_{t}+y_{3} E C_{t-1}+u_{t}----$ Equation-(6)

Where $E C_{T-1}=\ln y_{t-1}-\alpha \ln k_{t-1}-\beta \ln h_{t-1}-\ln C+u_{t}$

Equation 5 and 6 should in principle produce similar results as one equation has been obtained from the other. The data used in this paper has been obtained from the central statistical office in Mauritius and The Bank of Mauritius reports for the period 1990 to 2006. In the model, Y has been used as a proxy for real Gross Domestic Product (GDP) while $\mathrm{K}$ has been taken as the proxy for capital stock. Human capital stock is represented by $\mathrm{H}$ and $\mathrm{L}$ is a proxy for labour. In our analysis, we have used real GDP as a proxy for output. The gross domestic product (GDP) or gross domestic income (GDI) is one of the measures of national income and output for a given country's economy. GDP is defined as the total market value of all final goods and services produced within the country in a given period of time (usually a calendar year). It is also considered the sum of value added at every stage of production (the intermediate stages) of all final goods and services produced within a country in a given period of time, and it is given a money value. The most common approach in measuring and understanding GDP is the expenditure method: GDP = consumption + gross investment + government spending + (exports - imports $)$

Gross fixed capital formation (GDFCF) is a macroeconomic concept used in official national accounts. The statistical aggregate of GDFCF is a measure of the net new investment by enterprises in the domestic economy in fixed capital assets during an accounting period. While it is not possible to measure the value of the total fixed capital stock very accurately, it is possible to obtain a fairly reliable measure of the trend in new fixed investment. GFCF is a flow value. It is usually defined as the total value of additions to fixed assets by resident producer enterprises, less disposals of fixed assets during the quarter or year, plus additions to the value of non-produced assets (such as discoveries of mineral deposits, or land improvements). The figure below shows the trend in real GDP and GDFCF over the period 1990 to 2006 in Mauritius.

The measure of quantity of labour is the economically active population. In economics the people in the labour force are the suppliers of labour. Normally, the labour force of a country consists of everyone of working age typically above certain age (around 14 to 16) and below retirement age who are participating workers, people actively employed or looking for work.

Human capital refers to the stock of productive skills and technical knowledge embodied in labor. Labour is one of the three factors of production, and it is considered to be a fungible resource that is homogeneous and 
easily interchangeable. The human capital stock of Mauritius is defined as the average years of schooling of the total population aged 15 and above. The estimated average years of schooling have been used. Human capital is multifaceted and includes a complex set of human attributes; the genuine level of human capital is hard to measure in quantitative form. At best, average years of schooling are currently the most commonly employed measure it is problematic for at least two reasons. First, years of schooling do not raise human capital by an equal amount regardless of whether a person is enrolled in a primary, secondary or tertiary schooling level. Secondly, average years of schooling measures do not take into account quality changes within the educational system. This makes it difficult to interpret intertemporal comparisons. In terms of data availability, it seems difficult to account for the quality of educational patterns for Mauritius. Defining human capital stock implicitly gives the same weight to any year of schooling acquired by a person. Another way to measure human capital is through schooling rates (schooling enrolment ratios). Since these rates are easily available in many countries they have been use din numerous studies. The main drawback of these rates (real or gross) is that they only reflect the current flows of education. The accumulation of these flows is an element of human capital stock that will be available in the future. As education process evolves over various years, temporal lag between flows and stocks is generally very high. Even if an adequate temporal lag is considered, determining human capital stock requires an estimate of initial stock. In conclusion, the average years of schooling may provide a reasonable approximation of human capital stock, which also has the advantage of being interpreted more easily.

\section{RESULTS}

The Augmented-Dickey-Fuller (ADF) unit root test is performed to check for stationarity of the time series of each variable. If a variable exhibits strong trends, that is, they are non stationary and it implies that the use of conventional estimation methods in models that include such variables will tend to lead to erroneous statistical inference. Thus, in the presence of non- stationary variables, the use of conventional estimation methods brings the danger of obtaining "spurious regression" whose estimates are deprived of any economic meaning. Recent studies on time series analysis refer to co-integration techniques as the most adequate estimation method when variables of a model are non stationary. Hence, the ADF test was applied on each of the variables used in the model. The following test was made:-

Ho: there is a unit-root, that is, the time series is non-stationary

H1: there is no unit-root, that is, the time series is stationary

The results obtained are shown in table 1 below:

Table 1: Stationarity of the Time-Series

\begin{tabular}{|l|c|c|c|}
\hline \multicolumn{1}{|c|}{ Variables } & ADF Test Statistics & $\mathbf{9 5 \%}$ Critical Value & Results \\
\hline Lny & 0.59468 & -2.950 & non-stationary \\
\hline Lnk & -1.3568 & -2.950 & non-stationary \\
\hline Lnh & -3.2302 & -2.950 & non-stationary \\
\hline$\Delta \ln y$ & $-3.5026^{*}$ & -2.950 & stationary \\
\hline$\Delta \ln k$ & $-3.0789^{*}$ & -2.950 & stationary \\
\hline$\Delta \ln h$ & $-3.5512^{*}$ & -2.950 & stationary \\
\hline
\end{tabular}

From table one we note that real GDP, GDFCF that is capital stock and human capital are non-stationary. However, the results of Augmented Dickey-Fuller (ADF) test when applied to the variables indicate that first differenced series are stationary, that is, the variables will be integrated of at most first order. Comparing the values of obtained test statistics to the corresponding critical values, we conclude that all variables differenced once are stationary (that is, they do not have unit roots). Hence, we do not reject the null-hypothesis and conclude that the variables used in the model are non-stationary that is there is evidence of unit-root. However, the first difference series are stationary. 
Having applied the ADF unit root test, it is therefore possible to estimate the regression and obtain the residual. A test for cointegration for the model is carried out and the following results have been obtained.

Table 2: Co integration test

\begin{tabular}{|l|c|c|}
\hline & ADF & 95\% Critical DF \\
\hline Residuals $\left(\mu_{\mathrm{t}}\right)$ & -5.8965 & -5.2896 \\
\hline
\end{tabular}

From the above results we note that since the ADF test statistic exceed $95 \%$ critical DF, it can be concluded that cointegration exists among the variables in the model above. Cointegration allows estimate equilibrium, or long run parameters in a relationship that includes unit root (non-stationary) variables. At this stage, the use of this econometric analysis is motivated, on one hand, by interest in estimating long run relationships between real GDP, capital, human capital stock, and, on the other hand, by statistical properties of considered time series. The considered time series exhibit strong trends confirmed by tests for non-stationarity presented in Table 2 above.

The basic idea behind cointegration is that, in a long run, if two or more series evolve together, then a linear combination of them might be stable around a fixed mean, despite of their individual trends (that cause nonstationarity). Thus there could be one or more stationary linear combination of the series, suggesting stable long run relationship between them.

We next address the issue of multicollinearity. It arises when there is a high degree of correlation (either positive or negative) between two or more independent variables. The primary concern is that as the degree of multicollinearity increases, the regression model estimates of the coefficients become unstable and the standard errors for the coefficients can get wildly inflated. Hence, to detect multicollinearity problem we have run the variance inflation factor (VIF) or the detection-tolerance for multicollinearity test. A tolerance of less than 0.20 and/or a VIF of 5 and above indicates a multicollinearity problem. From table 4 the mean VIF obtained is 4.56 indicating that there is no problem of multicollinearity in our estimates. However, it should be noted that to avoid multicollinearity between capital and labour we have standardised output and the capital stock by labour units.

Subsequently we check for serial correlation using the Durbin-Watson statistic test. If the Durbin-Watson statistic is substantially less than 2, there is evidence of positive serial correlation. However, as a rule of thumb, if Durbin-Watson is less than 1.0, then there may be cause for alarm. The coefficient obtained for our regression model is 1.95 indicating that there is no problem of serial correlation in the model. After the serial correlation test, we estimated the Cobb-Douglas production function where our aim is to include human capital as an independent factor of production and the expected result should be positive and significant. That is, we expect to find that human capital do increase the amount of output in an economy hence leading to economic growth.

From table 3, below, an estimation of equation (5) in the standard growth equation is done by regressing $\log$ differences in real GDP on log differences of factors. This methodology is used in providing estimates for the magnitudes of $\alpha, \beta$ and 1- $\alpha-\beta$. Human capital as a production factor measured by average years of schooling appears to have a positive and significant impact on the growth of output per worker. The estimated long-run effect of 1 percent increase of the average years of schooling on GDP per unit of labour is approximately 0.328 percent, as shown in equation (7).

$$
\begin{aligned}
& \Delta \ln y_{t}=1.3313+0.84527 \Delta \ln k_{t}+1.6547 \Delta \ln h_{t}-0.52186 \ln y_{t-1}+0.25899 \ln k_{t-1}+ \\
& 0.0985 \ln h_{t-1}---- \text { Equation-(7) }
\end{aligned}
$$

The log differences in physical capital and human capital are shown to be positively correlated with log differences in output. The coefficient of the $\log$ difference of capital stock $\Delta \ln k_{t}$ enters positively and significantly at the 5\% confidence level. The coefficient of the log difference of capital stock is approximately 0.84527 . The $\log$ difference in human capital $\Delta \ln h_{t}$ enters significantly at the $5 \%$ confidence level, and with a positive coefficient which is approximately 1.6547. One explanation for the magnitude of this coefficient is that, over the years, 
Mauritius achieved an improvement in its educational level and this led to huge improvements in its stocks of human capital. It is also well-known that Mauritius did experience similar improvements in output, implying a high coefficient for $\Delta \ln h_{t}$.

The long-run relationship of output with respect to its explanatory variables can be derived from equation (5) in Table 3. The results in terms of the human capital augmented Cobb-Douglas production function are follows:

$$
Y=C K^{0.625} H^{0.203} L^{O .145}---- \text { Equation-(8) }
$$

Table 3: Production Function for Mauritius

\begin{tabular}{|c|c|c|c|}
\hline \multicolumn{4}{|c|}{ Human Capital as a factor input } \\
\hline Equation 5 & \multicolumn{3}{|c|}{ Dependent Variable: Percentage change of GDP/ Worker } \\
\hline & \multicolumn{2}{|c|}{ Coefficient } & \multirow{2}{*}{$\begin{array}{c}\text { Probability } \\
0.008\end{array}$} \\
\hline Constant & $\ln C$ & $\begin{array}{c}1.3313^{*} \\
(2.5655) \\
\end{array}$ & \\
\hline Percentage Change of Capital/Worker & $\Delta \ln k_{t}$ & $\begin{array}{c}0.84527 * \\
(5.6583) \\
\end{array}$ & 0.013 \\
\hline Percentage Change of Schooling/Worker & $\Delta \ln h_{t}$ & $\begin{array}{l}1.6547^{*} \\
(3.5708)\end{array}$ & 0.005 \\
\hline In GDP/Worker (-1) & $\ln y_{t-1}$ & $\begin{array}{c}-0.52186^{*} \\
(3.1581)\end{array}$ & 0.014 \\
\hline In capital/worker (-1) & $\ln K_{t-1}$ & $\begin{array}{c}0.25899^{*} \\
(2.7854)\end{array}$ & 0.006 \\
\hline In Average Schooling & $\ln h_{t-1}$ & $\begin{array}{l}0.0985 * \\
(0.8569) \\
\end{array}$ & 0.009 \\
\hline Long-run Elasticity of Capital & 0.652 & & \\
\hline Long-run Elasticity of schooling & 0.203 & & \\
\hline Adjusted $\mathrm{R}^{2}$ & 0.55185 & & \\
\hline F-Statistics & 7.8596 & & \\
\hline Durbin-Watson & 1.95254 & & \\
\hline $\mathrm{N}(1990-2006)$ & 17 & & \\
\hline \multicolumn{4}{|l|}{ t-statistics in parenthesis } \\
\hline$*$ Significant at the $5 \%$ level & & & \\
\hline
\end{tabular}

The adjusted $\mathrm{R}^{2}$ of the error-correction model and the F-statistics is on the high side. The test statistics does not show any evidence of serial correlation nor misspecification at conventional levels. The "one step" procedure of the error-correction model has been used. The findings confirm the traditional role given to human capital in the development process as a separate factor of production. In the first set of results, it is found hat human capital growth has a positive and significant effect in explaining per capital income growth.

Next we included an additional variable which is the ratio of imports/GDFCF to take into account two factors. Firstly, we analysed the changes when this variable is included. Normally, the overall result should continue to produce a significant and positive effect on output or economic growth in the economy. Moreover, we will use this model to analyse to what extent human capital affects the overall productivity of the economy. Human capital accumulation is commonly cited as a pre-requisite for development and most countries have government policies which encourage human capital accumulation. Besides, human capital is seen to facilitate the adoption and implementation of new technologies, which are continuously invented at exogenous rate. According to Nelson (1966), he suggested that the growth of technology depends on the level of education in a particular country. The basic framework for the second specification is a standard Cobb- Douglas production function with constant returns to scale.

$$
Y=C K^{\alpha} L^{\beta}---- \text { Equation }-(9)
$$


Where $\alpha$ and $\beta$ represent the elasticity of production relative to capital and labour respectively. This function is standardised by labour units in order to avoid multicollinearity between capital and labour. In per worker terms, this can be presented as follows:

$$
y=C k^{\alpha}---- \text { Equation }-(10)
$$

Where $y=Y / L$ and $k=K / L$ are output and physical capital respectively. Converted into logarithmic expression, the equation becomes:

$$
\ln y_{t}=\ln C+\alpha \ln k_{t}+u_{t}---- \text { Equation }-(11)
$$

Combining the long-run information of the variables with the short-run adjustment mechanism, the equation can be represented in its error-correction form:

$$
\Delta \ln y_{t}=\gamma 1 \Delta \ln k_{t}+\gamma 2\left(\ln y_{t-1}+\alpha \ln k_{t-1}-\ln C\right)---- \text { Equation-(12) }
$$

In contrast to the human capital augmented growth model however, total factor productivity is considered to be a function of exogenous variables, namely education and foreign inputs. Benhabib and Spiegel (1994) postulated that an educated labour force may play a key role in determining productivity rather than entering on its own as a production factor. They assumed that human capital is exogenously given and higher levels of years of schooling lead to an increased productivity. Equation 12 is transformed by including the additional variable which is the ratio of imports over investment. Hence, we have the one- step error correction model in its re-parameterised form:

$$
\Delta \ln y_{t}=a+\gamma 1 \Delta \ln k_{t}+\gamma 2 \Delta \ln y_{t}+\gamma 3 \ln k_{t}+\gamma 4 \ln h_{t}+\gamma 5 \ln I M_{t} / I_{t}+u_{t}---- \text { Equation-(13) }
$$

It can be noted, that the final equations are quite similar when compared with the human capital augmented model. The figure below shows the trend in the ratio of imports to investment in Mauritius over the year 1990-2006.

\section{Figure: 1}

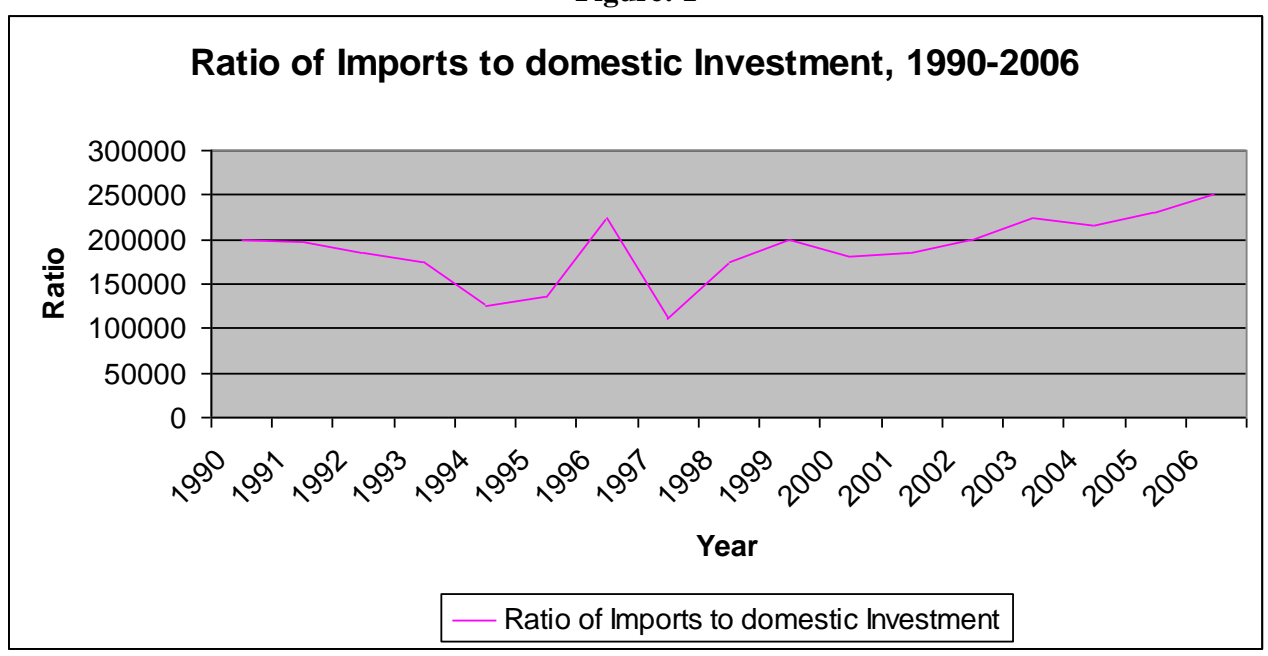

The average level of schooling should not be treated as an extra input into the production function but may directly affect total factor productivity. Based on the regression results of equation (13) in table 4 below, the following formulas in terms of the Cobb-Douglas production function can be obtained: 


$$
\begin{aligned}
& Y=C K^{0.7368} L^{0.2632}---- \text { Equation }-(15) \\
& \ln y=\ln C+0.7368 \ln k--------------------------------------(16) \\
& \Delta \ln y_{t}=-1.8636+1.79652 \Delta \ln k_{t}-0.78291 \Delta \ln y_{t-1}+0.56987 \ln k_{t-1}+1.3378 \ln h_{t} \\
& +0.0048 \ln I M_{t} / I_{t}---- \text { Equation }-(17)
\end{aligned}
$$

The production function in the long run is represented by equation (15) and equation (16) shows the shortterm dynamics of growth per labour unit. The estimated equation is accepted on statistical and economic grounds. It is noticed that the estimated production elasticity of physical capital in the long-run equation is now larger than its factor share (as estimated in the human capital augmented production function) reflecting its correlation with human capital. An estimation of equation (11) is made by regressing log of income on log of total factor productivity and physical capital. This methodology has provided estimates of the magnitudes of $\alpha$ and $(1-\alpha)$ where the factors appear to have a positive and significant impact on the growth of output per worker. In table 3 , the estimated production elasticity of physical capital in the long-run equation that is equation (5) is 0.652 . However, in table 4 , the estimated long-run effect of a one percent increase of the physical capital on GDP per unit of labour performs slightly better, approximately 0.7368 . An important factor influencing GDP growth is the 'disequilibrium error' from the

\begin{tabular}{|c|c|c|c|}
\hline \multicolumn{4}{|c|}{ Human Capital affecting the Technology Parameter } \\
\hline \multicolumn{4}{|c|}{ Dependent Variable: Percentage change of GDP/ Worker } \\
\hline & \multicolumn{2}{|c|}{ Coefficient } & \multirow{2}{*}{$\begin{array}{c}\text { Probability } \\
0.001\end{array}$} \\
\hline Constant & $c$ & $\begin{array}{c}-1.8636^{*} \\
(-4.3125)\end{array}$ & \\
\hline Percentage Change of Capital/Worker & $\Delta \ln k_{t}$ & $\begin{array}{c}1.79652^{*} \\
(6.3697)\end{array}$ & 0.002 \\
\hline In GDP/Worker (-1) & $\Delta \ln y_{t}$ & $\begin{array}{c}-0.78291 * \\
(-4.5288)\end{array}$ & 0.000 \\
\hline In capital/worker (-1) & $\ln k_{t-1}$ & $\begin{array}{c}0.56987 * \\
(4.1251)\end{array}$ & 0.003 \\
\hline In Average Schooling & $\ln h_{t}$ & $\begin{array}{l}1.3378^{*} \\
(4.8528)\end{array}$ & 0.009 \\
\hline Ratio of Imports/ Gross Domestic Investment & $I M_{t} / I_{t}$ & $0.0048252(0.21170)$ & 0.796 \\
\hline Long-run Elasticity of Capital & 0.7368 & & \\
\hline Adjusted $\mathrm{R}^{2}$ & 0.6852 & & \\
\hline F-Statistics & 9.2584 & & \\
\hline Durbin-Watson & $2.0086-$ & & \\
\hline S.E. of regression & 0.032307 & & \\
\hline $\mathrm{N}(1990-2006)$ & 17 & & \\
\hline \multicolumn{4}{|l|}{ t-statistics in parenthesis } \\
\hline * Significant at the $5 \%$ level & & & \\
\hline
\end{tabular}
previous period. The coefficient $(0.78291)$, in equation (17) from table 4 below determines the extent to which the disequilibrium in period $t-1$ for the period.

Table 4: Production Function for Mauritius

\section{CONCLUSION}

According to economic theory, human capital or educational attainment in an economy has long been viewed as an important factor in enhancing and promoting output or economic growth. In order to test this hypothesis, human capital was considered as an important role in economic growth mainly as an engine for improvement of the output level. The results obtained do support the argument. The significance of the analysis leads us to conclude that indeed human capital does lead to an increase in output of the Mauritian economy and 
hence it also facilitates the implementation of new technology in the country. We could find that capital formation has played a dominant role in explaining approximately sixty percent of Mauritius's growth rate of GDP, followed by the accumulation of human capital and labour force growth. There is compelling evidence that human capital increases productivity, suggesting that education really is productivity-enhancing rather than just a device that individuals use to signal their level of ability to the employer.

\section{AUTHOR INFORMATION}

Odit M.P is a full-time lecturer at the University of Technology, Mauritius. He received his MPhil degree from University of technology, Mauritius. He holds the degrees of MBA and BCom from Pune University, India. He has authored/co-authored in several journals and in the following areas which include corporate investment and financial leverage, treasury management, stock market development and economic growth, education and economic growth. He is a panel member in the field of corporate finance on the accreditation programs set by the Tertiary Education Commission in Mauritius.

Mrs K. Dookhan is a full-time Lecturer at the University of Technology, Mauritius. She holds a Bachelor of Commerce specializing in Banking and Finance and Cost and Works Accounting from the University of Pune, India, a Master in Business Administration (with First Class) in Finance from the University of Pune, India.

Ms. Sheereen Fauzel is an Educator and Head of Department at the Hindu Girls' College, Mauritius. She holds a Bachelor's degree in Economics and Finance from University of Mauritius and a Masters in Banking and Finance (with distinction) from University of Technology, Mauritius.

\section{REFERENCES}

1. Acemoglu, D. "Training and Innovation in an Imperfect Labour Market" Review of Economic Studies, 64, pp. $445-464,1997$

2. Aghion, Philippe, and Peter Howitt, (1998), Endogenous Growth Theory. Cambridge, MA: MIT Press.

3. Aurora Teixeira \& Natércia Fortuna, (2003), "Human Capital, Innovation Capability and Economic Growth," FEP Working Papers 131, Universidade do Porto, Faculdade de Economia do Porto.

4. Barro, R. J., (1991), "Economic growth in a Cross Section of Countries", Quarterly Journal of Economics vol. 106, no. 2, pp.407-443.

5. Barro, Robert J. and Xavier Sala-i-Martin, (1995), Economic Growth. New York: McGraw-Hill.

6. Becker, Gray S. (Colombia University Press. 1964), Human Capital, New York

7. Benhabib, Jess and Mark M. Spiegel, (1994), 'The Role of Human Capital in Economic Development: Evidence from Aggregate Cross-country Data.' Journal of Monetary Economics, Vol.34, pp. 143-173.

8. Bils, M. and P. Klenow, (2000), "Does Schooling Cause Growth?" American Economic Review, Vol. 90, No. 5, pp. 1160-1183.

9. Caselli, F., G. Esquivel and L. Fernando (1996), "Reopening the convergence debate: a new look at crosscountry growth empirics", Journal of Economic Growth, 1, 363-389.

10. Hanushek, Eric A. and Kimko, Dennis D., (2000), Schooling, labor force quality, and the growth of nations, American Economic Review, 90(5), 1184-1208.

11. Islam, N. (1995), “Growth Empirics: A Panel Data Approach”, Quarterly Journal of Economics, 110, pp. 1127-1170.

12. Jones, C. I., 1995, “Time Series Tests of Endogenous Growth Models", Quarterly Journal of Economics, Vol. 110, No. 2, pp. 495-525.

13. Krueger, Alan B., and Mikael Lindahl, (2001), "Education for growth: Why and for whom?" Journal of Economic Literature 39, no. 4 (December):1101-1136.

14. Lucas, Robert E. Jr., (1998), 'On the Mechanics of Economic Development.' Journal of Monetary Economics, Vol. 22, pp. 3-42.

15. Mankiw, N. Gregory, David Romer, and David N. Weil, (1992), 'A Contribution to the Empirics of Economic Growth.’ Quarterly Journal of Economics, Vol. 107, pp. 407-437.

16. McMahon, Walter W. and Appiah, Elizabeth M., "The Social Outcomes of Education and Feedbacks on Growth in Africa” (April 2002). Journal of Development Studies, Vol. 38, No. 4, April 2002 
17. Mincer, Jacob, (1974), Schooling Experience and Earnings. New York: NBER.

18. Nelson, Richard and Edmund Phelps, (1966), "Investments in Humans, Technological Diffusion, and Economic Growth.” American Economic Review: Papers and Proceedings, Vol. 61, pp. 69-75.

19. Pritchett, L., (2001), "Where Has All the Education Gone?" World Bank Economic Review, Vol. 15, No. 3, pp. 367-391.

20. Redding, Stephen, (1996) "The low-skill, low-quality trap: strategic complementarities between human capital and R \& D", Economic Journal, 106 (435). pp. 458-470

21. Romer, Paul M, (1990), 'Endogenous Technological Change,' Journal of Political Economy, Vol. 98, No. 5, pp. S71-S102.

22. Romer, Paul M. "Should the Government Subsidize Supply or Demand in the Market for Scientists and Engineers? NBER Working Paper 7723, June 2000.

23. Rustichini, A., and J.A. Schmitz. "Research and Imitation in Long-run Growth." Journal of Monetary Economics 27, 271-292, 1991.

24. Solow, R. M. (1957): "Technical Change and the Aggregate Production Function," Review of Economics and Statistics, 39(3), 312-320.

25. Solow, Robert M., (1956), 'A Contribution to the Theory of Economic Growth.' Quarterly Journal of Economics, Vol. 70, pp. 65-94.

26. Temple, J. R. (2001), “Generalizations that aren't? Evidence on education and growth”, European Economic Review, Vol. 45, No. 4-6, pp. 905-918.

27. Uzawa, H., (1965), "Optimum technical change in an aggregative model of economic growth", International Economic Review, 6, pp. 18-31.

28. Von Ludger J. Loening, (2002), 'The impact of Education on Economic Growth in Guatemala: A TimeSeries' Analysis Applying an Error-Correction Methodology.

29. Weir, S. \& Knight, J., (2000). "Adoption and Diffusion of Agricultural Innovations in Ethiopia: The Role of Education," Working Papers Series 2000-5, Centre for the Study of African Economies, University of Oxford. 